\title{
PELATIHAN STANDAR HIGIENE DAN SANITASI UNTUK PENINGKATAN PEMBERDAYAAN UKM OLAHAN IKAN PATIN
}

\author{
Roza Elvyra*, Dewi Indriyani Roslim, Nazaruddin \\ Program Studi Biologi Fakultas MIPA Fakultas Teknik \\ Universitas Riau \\ email: roza.elvyra@gmail.com
}

\begin{abstract}
Training of hygiene and sanitation standard is carried out as a community service activity by the University towards UKM of patin fish processed in Kampung Patin, Koto Mesjid Village, XIII Koto Kampar District, Kampar Regency of Riau Province. The training participants are members of the UKM Negeri Patin and UKM Mr. Patin. UKM products are nuggets, meatballs, shredded, crackers and fillets from patin fish. The training is carried out as a form of knowledge transfer about hygiene and sanitation standards as well as the method and requirements for the processing of marketing permits for food products to increase empowerment of UKM of patin fish processed. This training collaborates with presenters from BBPOM in Pekanbaru. From the results of the questionnaire, it was found that the trainees gained an increase in knowledge, that is from 35\% of participants who had understood the previous hygiene and sanitation standards, it increased to $95 \%$ of participants who really understood after the training. UKM members also received additional knowledge about the method and requirements for processing food marketing permits, that is from $20 \%$ of participants who already knew before the training increased to $95 \%$ of participants who understood after the training.
\end{abstract}

Keywords: UKM, patin fish processed, Riau

\begin{abstract}
Abstrak
Pelatihan standar higiene dan sanitasi dilaksanakan sebagai kegiatan pengabdian kepada masyarakat oleh Perguruan Tinggi terhadap UKM Olahan Ikan Patin di Kampung Patin, Desa Koto Mesjid, Kecamatan XIII Koto Kampar, Kabupaten Kampar Provinsi Riau. Peserta pelatihan adalah anggota dari UKM Negeri Patin dan UKM Mr. Patin. Produk UKM berupa nugget, bakso, abon, kerupuk kulit dan fillet dari bahan baku ikan patin. Pelatihan dilaksanakan sebagai bentuk transfer pengetahuan mengenai standar higiene dan sanitasi serta cara dan persyaratan pengurusan izin edar produk pangan untuk peningkatan pemberdayaan UKM olahan ikan patin. Pelatihan ini bekerjasama dengan pemateri dari BBPOM di Pekanbaru. Dari hasil kuisioner diketahui bahwa peserta pelatihan mendapatkan peningkatan pengetahuan yaitu dari 35\% peserta yang sudah memahami mengenai standar higiene dan sanitasi sebelumnya, meningkat menjadi 95\% peserta yang betul-betul memahami setelah pelatihan. Anggota UKM juga mendapatkan tambahan pengetahuan mengenai cara dan persyaratan pengurusan izin edar produk pangan, yatitu dari $20 \%$ peserta yang sudah mengetahuinya sebelum pelatihan meningkat menjadi $95 \%$ peserta yang memahami setelah pelatihan
\end{abstract}

Kata kunci: UKM, olahan ikan patin, Riau

\section{PENDAHULUAN}

UKM Negeri Patin dan UKM Mr. Patin berada di Kampung Patin Desa Koto Mesjid Kecamatan XIII Koto Kampar, Kabupaten Kampar Provinsi Riau. Kedua UKM ini sama-sama menghasilkan produk pangan dari olahan ikan patin. Produk pangan yang telah dihasilkan selama ini oleh UKM tersebut adalah nugget, bakso, abon, kerupuk kulit dan fillet dengan sumber bahan bakunya yaitu dari ikan patin. 
Ikan patin yang digunakan oleh UKM adalah ikan patin siam. Ikan patin siam merupakan jenis Pangasius hypophthalmus, yang merupakan sinonim dari Pangasius sutchi (Rukmana dan Yudirachman, 2016). Ikan patin Pangasius merupakan anggota dari Ordo Siluriformes dan Famili Pangasidae (Kottelat et al. 1993).

Menurut Kordi (2015) ikan patin yang merupakan anggota catfish ini adalah ikan yang mampu hidup pada lingkungan perairan dengan kualitas air yang buruk, sehingga dapat dipelihara pada air yang tergenang, dimana patin ini dapat hidup pada perairan dengan kondisi kandungan oksigen $<3 \mathrm{ppm}$. Sedangkan Saparinto (2017) menjelaskan bahwa ikan patin merupakan jenis ikan air tawar berbadan memanjang yang selain bernafas dengan insang, alat pernafasannya juga dilengkapi dengan alat tambahan sehingga dapat mengambil $\mathrm{O}_{2}$ dari udara. Kondisi perairan yang ideal untuk kehidupan ikan ini adalah suhu $26-32^{\circ} \mathrm{C}$, pH 6,7-8,6, kandungan $\mathrm{O}_{2}$ yaitu 3-6 ppm serta kadar $\mathrm{CO}_{2}$ yaitu 9-20 ppm.

Kegiatan pengabdian masyarakat yang dilakukan oleh Universitas Riau terhadap UKM mitra merupakan bentuk transfer ilmu pengetahuan dari Perguruan Tinggi kepada masyarakat, dalam hal ini UKM olahan ikan patin. Dengan adanya kegiatan ini kedepannya diharapkan terjadinya percepatan alih teknologi dan transfer ilmu pengetahuan dari Perguruan Tinggi kepada masyarakat sehingga terjadi peningkatan pemberdayaan UKM untuk menjadi industri unggulan daerah. Pelaksanaan kegiatan ini dilakukan untuk peningkatan mutu produk pangan UKM maupun peningkatan kualitas sumberdaya manusia pada kelompok usaha olahan ikan patin tersebut, sehingga pengetahuan dan pemahaman masyarakat pada kelompok UKM terhadap iptek juga akan meningkat, yang akan mengakibatkan peningkatan skill atau keterampilan anggota UKM tersebut.

Produk UKM dari daerah ini mempunyai potensi untuk dikembangkan menjadi produk unggulan daerah di Provinsi Riau. Untuk upaya pengembangan produk UKM menjadi produk unggulan daerah maka diperlukan transfer ilmu pengetahuan mengenai standar higiene dan sanitasi produk pangan melalui pelatihan. Selain itu, produk pangan perlu mendapatkan izin edar dari lembaga yang berwenang yaitu Badan Pengawasan Obat dan Makanan (BPOM). Oleh karena itu perlu dilakukan kegiatan pengabdian kepada masyarakat ini dengan bekerjasama dengan pemateri dari Balai Besar Pengawasan Obat dan Makanan (BBPOM) di Pekanbaru. Materi yang diberikan pada pelatihan adalah mengenai standar higiene dan sanitasi, serta materi cara dan persyaratan pengurusan izin edar produk pangan dari BPOM RI.

\section{METODE PENELITIAN}

Kegiatan pengabdian kepada masyarakat yang dilakukan merupakan bagian dari Program Pengembangan Produk Unggulan Daerah (PPPUD) Universitas Riau. Kegiatan pengabdian kepada masyarakat terhadap kelompok UKM olahan ikan patin ini dilakukan pada bulan Agustus 2018. UKM yang dipilih sebagai mitra dalam kegiatan ini adalah UKM Negeri Patin dan UKM Mr. Patin. Lokasi kegiatan yaitu di Kampung Patin Desa Koto Mesjid, Kecamatan XIII Koto Kampar Kabupaten Kampar Provinsi Riau.

Kegiatan pengabdian kepada masyarakat ini ditujukan untuk memberikan pengetahuan kepada masyarakat dalam hal ini yaitu anggota UKM Negeri Patin dan UKM Mr. Patin sebanyak 20 peserta. Materi yang disampaikan adalah mengenai standar 
higiene dan sanitasi untuk produk olahan ikan patin, serta cara dan persyaratan pengurusan izin edar produk pangan dari BPOM RI. Metode yang dilakukan dalam kegiatan pelatihan terdiri dari:

1. Pemberian materi dengan cara ceramah. Pemaparan materi dilakukan dengan penyajian powerpoint yang dilengkapi dengan gambar-gambar yang terkait materi, dengan menggunakan laptop dan infocus supaya materi menjadi lebih menarik. Metode ini dapat membantu peserta pelatihan untuk dapat memahami materi dengan lebih baik.

2. Interaksi antara tim pelaksana dan peserta melalui metode diskusi dan tanya jawab. Metode ini dilakukan agar dapat diketahui bagian materi mana yang sudah dipahami dan bagian mana yang belum dipahami, sehingga materi yang belum dipahami bisa lebih diperjelas lagi penyampaiannya.

3. Pendistribusian kuisioner kepada peserta pelatihan. Kuisioner ini diisi oleh peseta pada ssat sebelum pelatihan dan setelah pelatihan. Data dari kuisioner yang sudah diisi oleh peserta sebelum dan setelah pelatihan, selanjutnya ditabulasi dan diolah dalam bentuk grafik, kemudian dianalisis untuk mengetahui peningkatan pemahaman peserta terhadap materi pelatihan yang telah diberikan.

\section{HASIL DAN PEMBAHASAN}

Kegiatan pengabdian kepada masyarakat telah dilakukan yaitu transfer ilmu pengetahuan dari perguruan Tinggi melalui pelatihan terhadap kelompok UKM Negeri Patin dan UKM Mr. Patin, di Kampung Patin,
Desa Koto Mesjid, Kecamatan XIII Koto Kampar, Kabupaten Kampar Provinsi Riau (Gambar 1). Tema pelatihan yang diberikan adalah Iptek bagi Produk Unggkan Daerah. Dalam pelatihan ini selain pemateri dari Tim Pengabdian Program Pengembangan Produk Unggulan Daerah (PPPUD) Universitas Riau, juga bekerjasama dengan pemateri dari BBPOM yaitu dari Bagian Sertifikasi BBPOM Pekanbaru.

Materi yang disampaikan dalam pelatihan adalah mengenai standar higiene dan sanitasi produk pangan, serta cara dan persyaratan pengurusan izin edar produk pangan dari BPOM RI. Kelayakan standar higiene dan sanitasi produk pangan dari UKM akan diperlukan sebagai persyaratan untuk pengurusan izin edar makanan dalam negeri (MD) dari BPOM RI. Nilai produk pangan akan bertambah, apabila pada kemasannya mempunyai kelengkapan perizinan untuk produk pangan yang telah ditentukan, dan menambah kepercayaan konsumen terhadap jaminan keamanan pangan.
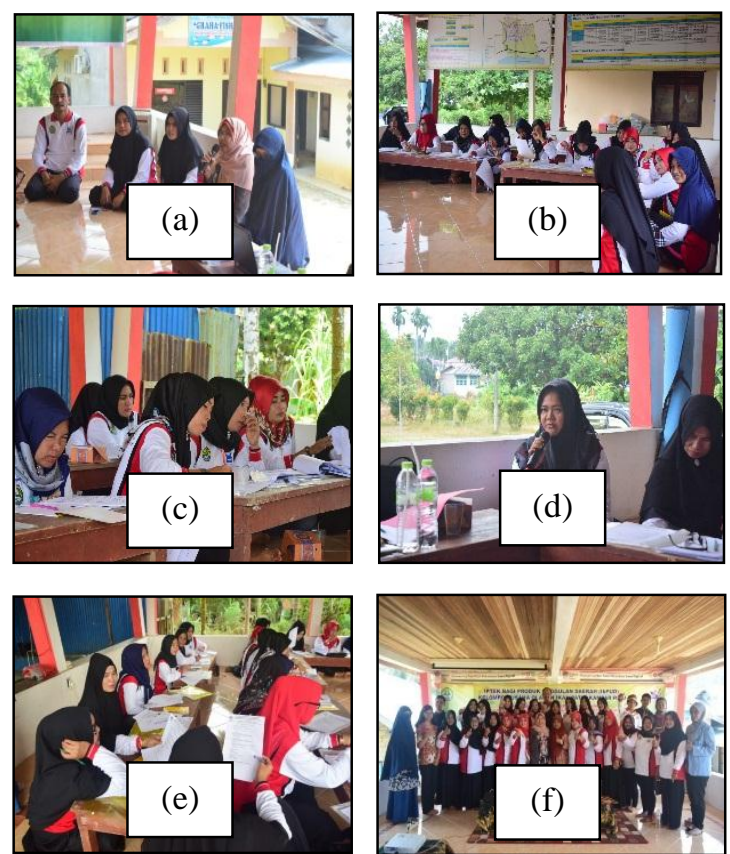

Gambar 1. Pelatihan standar higiene dan sanitasi kepada UKM Negeri Patin dan UKM Mr. Patin; a. Pengarahan dari ketua pelaksana kegiatan, b- 
c. Suasana Pelatihan, d. Pertanyaan oleh Peserta, e. Pengisian kuisioner oleh peserta, f. Foto bersama tim pelaksana kegiatan dengan anggota UKM

Tingkat keberhasilan pelaksanaan kegiatan pelatihan standar higiene dan sanitasi untuk produk olahan ikan patin ini dapat diketahui dari isian kuisioner oleh peserta pelatihan yang hadir. Kuisioner diisi oleh peserta pada saat sebelum pelatihan dan setelah pelatihan. Dari hasil kuisioner tersebut dapat dianalisis tingkat pemahaman peserta pelatihan terhadap materi yang diberikan.

Berdasarkan data isian kuisioner dari pemberian materi mengenai standar higiene dan sanitasi produk pangan, diperoleh data bahwa sebagian kecil peserta yaitu $35 \%$ peserta yang mengetahui mengenai standar higiene dan sanitasi sebelum pelatihan. Sebagian besar peserta yaitu sebanyak $65 \%$ tidak mengetahui mengenai standar higiene dan sanitasi sebelum mengikuti pelatihan (Gambar 2).

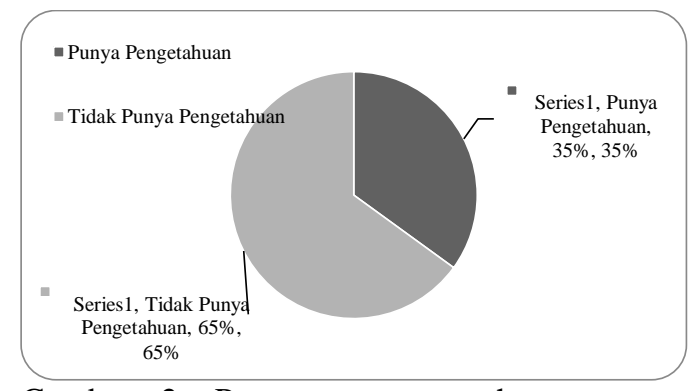

Gambar 2. Persentase pengetahuan peserta mengenai standar higiene dan sanitasi produk pangan sebelum mengikuti pelatihan

Berdasarkan isian kuisioner diperoleh data sebesar $95 \%$ peserta mendapat tambahan pengetahuan mengenai standar higiene dan sanitasi produk pangan setelah mengikuti pelatihan (Gambar 3). Hal ini menunjukkan bahwa setelah peserta mengikuti pelatihan, diperoleh peningkatan pengetahuan peserta mengenai materi yang disampaikan.

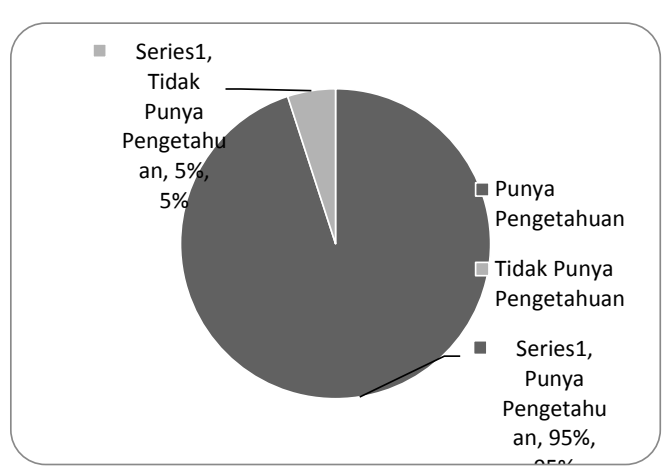

Gambar 3. Persentase pengetahuan peserta mengenai standar higiene dan sanitasi produk pangan setelah mengikuti pelatihan

Pada Lampiran IV Peraturan Kepala Badan Pengawas Obat dan Makanan Republik Indonesia Nomor 12 Tahun 2016 telah dijelaskan bahwa persyaratan label pangan olahan, salah satunya harus memuat nomor izin edar. Hasil isian kuisioner dari pemberian materi mengenai cara dan persyaratan pengurusan izin edar produk pangan, diperoleh data bahwa sebagian kecil peserta yaitu $20 \%$ peserta yang mempunyai pemahaman mengenai pengurusan izin edar produk pangan sebelum pelatihan. Sebagian besar peserta yaitu sebanyak $80 \%$ kurang memahami mengenai pengurusan zin edar produk pangan sebelum mengikuti pelatihan (Gambar 4).

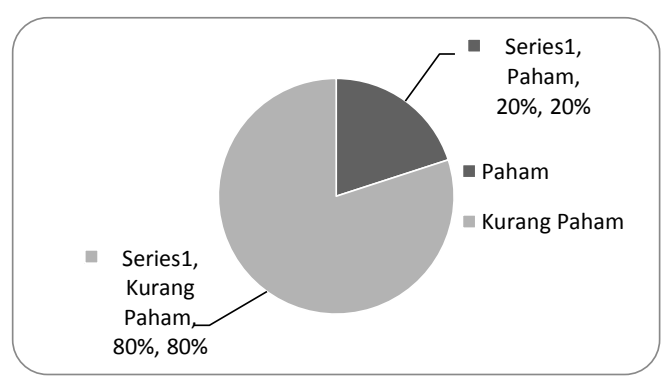

Gambar 4. Persentase pemahaman peserta mengenai pengurusan izin edar produk pangan sebelum mengikuti pelatihan 


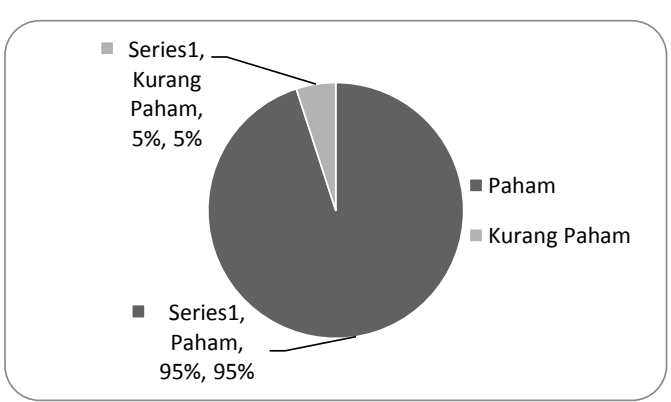

Gambar 5. Persentase pemahaman peserta mengenai pengurusan izin edar produk pangan setelah mengikuti pelatihan

Berdasarkan isian kuisioner peserta diperoleh data sebanyak $95 \%$ peserta memahami cara dan persyaratan pengurusan izin edar produk pangan setelah mengikuti pelatihan (Gambar 5). Hal ini juga menunjukkan bahwa setelah pelatihan diberikan kepada peserta, diperoleh peningkatan pemahaman peserta mengenai pengurusan izin edar produk pangan.

Dari analisis isian kuisioner, dapat diketahui bahwa pelatihan mengenai standar higiene dan sanitasi serta cara dan persyaratan pengurusan izin edar produk pangan yang diberikan kepada peserta pelatihan telah berhasil meningkatkan pengetahuan bagi peserta yang sudah punya pengetahuan sebelumnya, dan berhasil menambah pengetahuan dan pemahaman bagi peserta yang belum punya pengetahuan sama sekali sebelumnya. Seluruh peserta menyatakan puas dan berminat mengikuti pelatihan selanjutnya yang berkaitan dengan pengembangan usaha produk olahan ikan patin. Dari seluruh data kuisioner dapat disimpulkan bahwa pelatihan yang diberikan kepada peserta pelatihan telah berhasil dilaksanakan dengan sangat baik. Hal ini mendorong minat para peserta untuk mengikuti kegiatan selanjutnya. Tim pelaksana kegiatan pengabdian PPPUD menganalisis bahwa anggota UKM mempunyai keinginan untuk lebih baik menjalankan usaha mereka kedepannya.
Pelatihan yang diberikan dapat meningkatkan pemberdayaan UKM olahan ikan patin sebagai upaya penguatan sumberdaya manusia pada UKM, agar dapat ditingkatkan menjadi industri unggulan daerah.

\section{SIMPULAN}

Dari kegiatan pengabdian kepada masyarakat telah dilakukan transfer ilmu pengetahuan dari Perguruan Tinggi kepada masyarakat kelompok UKM yang merupakan mitra kegiatan yaitu dalam bentuk pelatihan mengenai standar higiene dan sanitasi untuk produk olahan ikan patin, serta cara dan persyaratan pengurusan izin edar produk pangan. Peserta pelatihan berpartisipasi aktif dalam mengikuti kegiatan pelatihan. Sebanyak $95 \%$ peserta menyatakan memperoleh peningkatan pemahaman mengenai standar higiene dan sanitasi, dan juga sebanyak 95\% peserta memperoleh peningkatan pemahaman mengenai cara dan persyaratan pengurusan izin edar produk pangan. Pelatihan yang diberikan dapat meningkatkan pemberdayaan UKM olahan ikan patin sebagai upaya penguatan sumberdaya manusia pada UKM.

\section{UCAPAN TERIMAKASIH}

Ucapan terimakasih disampaikan kepada Direktorat Riset dan Pengabdian kepada Masyarakat, Kementerian Riset, Teknologi dan Pendidikan Tinggi, Republik Indonesia yang telah membiayai kegiatan ini melalui Hibah Pengabdian kepada Masyarakat, Program Pengembangan Produk Unggulan Daerah (PPPUD) Kelompok Usaha Olahan Ikan Patin Kampar Riau Tahun 2018 atas nama Roza Elvyra. 


\section{DAFTAR PUSTAKA}

[1] Kordi, KMGH. 2015. Akuakultur Intensif dan Super Intensif: Produksi Tinggi Dalam waktu Singkat. Penerbit Rineka Cipta. Jakarta.

[2] Kottelat M, Whitten AJ, Kartikasari SN, Wirdjoatmodjo S. 1993. Freshwater Fishes of Western Indonesia and Sulawesi. Periplus edition (HK) in collaboration with the environment Rep. of Indonesia. Jakarta.

[3] Peraturan Kepala Badan Pengawas Obat dan Makanan Republik Indonesia, Nomor 12 Tahun 2016 Tentang Pendaftaran Pangan Olahan.

[4] Rukmana HR. dan Yudirachman HH. 2016. Sukses Budi Daya Ikan Patin Secara Intensif. Penerbit Lily Publisher. Yogyakarta.

[5] Saparinto, C. 2017. Pembesaran 6 Ikan Konsumsi di Pekarangan. Penerbit Penebar Swadaya. Jakarta. 